\title{
Using transfer entropy to measure the patterns of information flow though cortex: application to MEG recordings from a visual Simon
} task

\author{
M Wibral1, Raul Vicente*2, Jochen Triesch² and Gordon Pipa ${ }^{2,3,4}$
}

\author{
Address: ${ }^{1}$ MEG Unit, Brain Imaging Ctr. Frankfurt, Frankfurt, Germany, ${ }^{2}$ Frankfurt Inst. for Advanced Studies, Frankfurt, Germany, \\ ${ }^{3}$ Neurophysiology Department, Max Planck Inst. for Brain Research, Frankfurt, Germany and ${ }^{4}$ Department of Anesthesia, Massachusetts General \\ Hosp., Cambridge, MA, USA \\ Email: Raul Vicente* - raulvicente@gmail.com \\ * Corresponding author
}

from Eighteenth Annual Computational Neuroscience Meeting: CNS*2009

Berlin, Germany. 18-23 July 2009

Published: 13 July 2009

BMC Neuroscience 2009, I0(Suppl I):P232 doi:I0.II86/I47I-2202-I0-SI-P232

This abstract is available from: http://www.biomedcentral.com//47I-2202/I0/SI/P232

(c) 2009 Wibral et al; licensee BioMed Central Ltd.

Functional connectivity of the brain describes the network of correlated activities of different brain areas. However, correlation does not imply causality and most synchronization measures do not distinguish causal and non-causal interactions among remote brain areas, i.e. determine the effective connectivity [1]. Identification of causal interactions in brain networks is fundamental to understanding the processing of information. Attempts at unveiling signs of functional or effective connectivity from non-invasive Magneto-/Electroencephalographic (M/EEG) recordings at the sensor level are hampered by volume conduction leading to correlated sensor signals without the presence of effective connectivity. Here, we make use of the transfer entropy (TE) concept to establish effective connectivity. The formalism of TE has been proposed as a rigorous quantification of the information flow among systems in interaction and is a natural generalization of mutual information [2]. In contrast to Granger causality, TE is a non-linear measure and not influenced by volume conduction.

We evaluate TE on MEG data recorded during a Simon task. Subjects were presented with a "L" or "R" letter in either the left or the right side of a screen and had to press a left-side key in response to the "L" letter and the rightside key in response to the " $\mathrm{R}$ " letter, independently of the spatial location of the stimulus. The sequential organiza- tion of this task allows us to infer gross effective connectivity: Visual input has to be processed and the letter recognized before motor action can be planned. Hence, effective connectivity from visual cortices to frontal and motor areas was expected. Our tasks directed visual input either to the left or right hemisphere in early visual cortex and required left or right hemispheric motor responses, presumably changing connectivity patterns.

TE of channel pairs was computed with a KozachenkoLeonenko estimator while the statistical significance of the causal interactions was determined by a non-parametric permutation test. The flow of information revealed that different neuronal circuits (including long-range causal influences like inter hemispheric temporal lobe interactions) were recruited for the four different experimental conditions, in accordance to the physiological expectation. The effective networks of Simon versus nonSimon effect conditions were also compared to explore the use of effective connectivity as a tool to investigate cognitive processes.

\section{Acknowledgements}

Supported by the Hertie Foundation, the EU (GABA project FP6-2005NEST-Path-043309), the German Ministry for Education and Research (BMBF grants 0IGQ0I4I3), and the Stifterverband fur die Deutsche Wissenschaft. 


\section{References}

I. Friston KJ: Functional and effective connectivity in neuroimaging: a synthesis. Hum Brain Map 1994, 2:56-78.

2. Schreiber T: Measuring information transfer. Phys Rev Lett 2000, 85:46I-464.

Publish with Bio Med Central and every scientist can read your work free of charge

"BioMed Central will be the most significant development for disseminating the results of biomedical research in our lifetime. " Sir Paul Nurse, Cancer Research UK

Your research papers will be:

- available free of charge to the entire biomedical community

- peer reviewed and published immediately upon acceptance

- cited in PubMed and archived on PubMed Central

- yours - you keep the copyright

Submit your manuscript here:

http://www.biomedcentral.com/info/publishing_adv.asp 